\title{
Evaluating webcams as an acessibility resource in inclusive schools
}

\section{GUILHERME H. H. SANTANA*, HEIKO HORNUNG.}

\begin{abstract}
This research aims to collect data about previous researches and low-cost solutions related to the use of a webcam as an assistive technology to further facilitate the use of computers, allowing physically disabled people to express and comunicate efficiently through technology. It also evaluates the solutions found in the context of public schools.
\end{abstract}

\author{
Key words: \\ accessibility, webcam, low-cost solution.
}

\section{Introduction}

In Brazil, three quarters of the schools do not have basic accessibility items, such as ramps, handrails and signalization. Less than a third have adapted bathrooms for people with disabilities ${ }^{1}$.

In this context, it's hard to expect an efficient teaching method for children with disabilities. There is a lack for resources and specialized professionals, and this increases social exclusion in an unmeasurable way.

In this research, we sought for studies and low-cost technological solutions capable of increasing digital inclusion and the very capacity of the student to express his thoughts and develop his intellect. Using a webcam, a relatively cheap device that is available in most public schools, we had as a mission to find a way to improve computer accessibility to physically disabled people.

\section{Results and Discussion}

Facial features tracking softwares were proposed and developed since the invention of the webcam. Solutions as Camera Mouse $^{2}$, FaceMOUSE ${ }^{3}$ and Kinesic Mouse ${ }^{4}$ use efficient algorithms that continuously track a region of the face and move the mouse pointer accordingly.

Simultaneously, assistive solutions that use devices beyond the webcam were also developed, among which we highlight EagleEyes ${ }^{5}$, a hardware-software solution that measures EOG (electro-oculographic potential) to move the mouse pointer to the exact place in the screen where the user is looking at, regardless of his head position.

Whilst more efficient, these type of solutions do not serve our purposes: they are invasive, use external devices beyond the webcam and, most importantly, have a high cost associated with them.

Given that scenario, we focused our research in softwares that used only a webcam to provide accessibility. Among the ones listed above, the Camera Mouse solution showed itself as the most fitting to our demands - besides being efficient and non-invasive (an important feature as we're dealing with children), it is free and constantly updated, unlike its competitors.

Upon initializing, it asks the user to choose a face feature to track, and then the user is ready to move the pointer with subtle movements of the face.

Actions like clicks, double-clicks and right button clicks are provided by the software itself. Keyboard usage is provided by third-part solutions, such as Midas Touch, that is specially adapted for users that use softwares like Camera Mouse to type.

During our tests we performed some simple tasks, such as reading an e-mail, opening a website and writing a small text. The former two were accomplished with ease and little difference in time when compared with the time spent when using a mouse. The use of the favorites bar helped to achieve this efficiency in time. The latter, although as easy, took a considerable greater time to be done. This result, however, was expected, given the dwell time of each click.
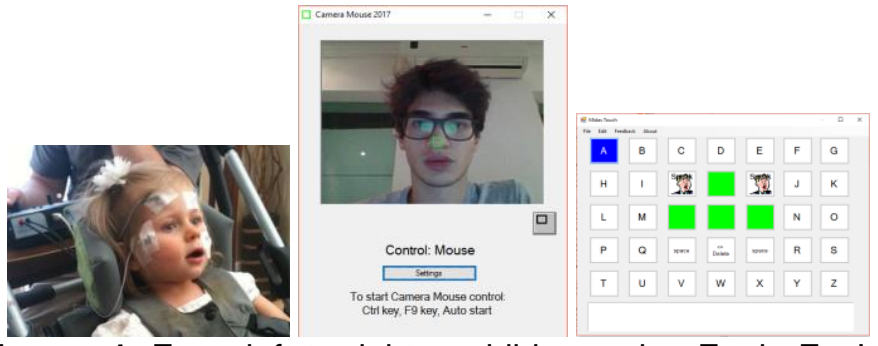

Image 1. From left to right: a children using Eagle Eye's sensor; Camera Mouse initial interface; Midas Touch keyboard.

\section{Conclusions}

With public school children as our target audience, Camera Mouse with Midas Touch showed themselves as the best low-cost, webcam-only solution. The installation and configuration process is extremely simple, demanding little effort from their teachers. The adaptation process is fast and made even easier with little games and puzzles made available by its creator.

The implementation and further use of this solution may increase digital inclusion of physically disabled children, making possible for them to express thoughts and emotions as well as allowing them to develop their intellect with less effort.

\footnotetext{
$\overline{1}$ Reis, Thiago. Moreno, Ana C. (2015, August 19). A escola acessível (ou não). Retrieved from http://especiais.g1.globo.com/educacao/2015/censoescolar-2014/a-escola-acessivel-ou-nao.html

2 Betke, Margrit, James Gips, and Peter Fleming. "The camera mouse: visual tracking of body features to provide computer access for people with severe disabilities." IEEE Transactions on neural systems and Rehabilitation Engineering 10.1 (2002).

${ }^{3}$ FaceMOUSE: ausilio informatico per paralisi cerebrale infantile. (2017, June 30). Retrieved from http://www.paralisicerebraleinfantile.it/

${ }_{4}^{4}$ The head and face controlled computer mouse. (2017, June 30). Retrieved from http://kinesicmouse.xcessity.at/.

5 EagleEyes Project. (2017, May 21). Retrieved from http://www.bc.edu/schools/csom/eagleeyes/.
} 